\title{
Automated Monitoring of Coastal Aquifers with Electrical Resistivity Tomography
}

R. D. Ogilvy ${ }^{1}$, P. I. Meldrum ${ }^{1}$, O. Kuras ${ }^{1}$, P. B. Wilkinson ${ }^{1}$, J. E. Chambers ${ }^{1}$, M. Sen ${ }^{1}$, A. Pulido-

Bosch $^{2}$, J. Gisbert ${ }^{2}$, S. Jorreto ${ }^{2}$, I. Frances ${ }^{2}$ and P. Tsourlos ${ }^{3}$

${ }^{1}$ British Geological Survey, Keyworth, Nottingham, NG12 5GG, United Kingdom. * Email: rdo@bgs.ac.uk

${ }^{2}$ Department of Hydrogeology, University of Almería, Spain

${ }^{3}$ Department of Geophysics, School of Geology, Aristotle University of Thessaloniki, GR-54124 Thessaloniki,

Greece.

\section{ABSTRACT}

An Automated time-Lapse Electrical Resistivity Tomography (ALERT) system has been developed for the long-term monitoring of coastal aquifers. This ALERT system has been permanently installed in the River Andarax, Almeria, Spain to monitor and manage the impact of climatic change and landuse practice on the underlying Quaternary aquifer. An electrode array, nearly $1.6 \mathrm{~km}$ long, has been buried below the normally dry river bed with electrode take-outs at regular intervals of $10 \mathrm{~m}$. The maximum depth of investigation is about $160 \mathrm{~m}$ below ground level. An unmanned, permanent control station, in a secure location, allows the aquifer to be interrogated remotely from the BGS office in the UK. Volumetric geoelectric images of the subsurface can be obtained "on demand" or at regular intervals; thereby eliminating the need for expensive repeat surveys. The entire process from data capture to image on the office PC is fully automated and seamless. The ALERT technology can provide early warning of potential threats to vulnerable water systems such as over-exploitation, rising sea levels, anthropogenic pollutants and seawater intrusion. The electrical images obtained (in space and time) are interpreted in terms of the hydrogeologic features including the seawater-freshwater interface. The timely detection and imaging of groundwater changes can help to regulate pumping and irrigation schemes.

Key words: automated electrical tomography, time-lapse monitoring, aquifers 


\section{INTRODUCTION}

ALERT aims to develop a radically different strategy for monitoring and managing the impact of climatic change and land-use practice on scarce water resources. Monitoring groundwater properties by traditional borehole or well sampling is time-consuming, expensive and infrequent. Time-lapse surveys are now routinely deployed in geophysics (Johansson and Dahlin, 1996, Tsourlos et al, 2003, Grellier et al 2008) but the cost of manual repeat surveys can be prohibitively expensive. To overcome these limitations, innovative ALERT technology has been designed which allows the near real-time measurement of geoelectric, hydrologic and other properties "on demand", thereby giving early warning of potential threats to vulnerable water systems. Permanent in-situ geoelectric measurements are used to provide surrogate indicators of hydrochemical and hydrogeological properties. The ALERT survey concept uses electrode arrays, permanently buried in shallow trenches or attached to borehole casing (Kuras et al 2005, Ogilvy et al, 2007, 2008). This network is then interrogated from the office by wireless telemetry to provide volumetric images of the subsurface at regular intervals (Fig. 1). Once installed, no manual intervention is required; data is transmitted automatically according to a pre-programmed schedule and for specific survey parameters, both of which may be varied remotely as conditions change (i.e: an adaptive sampling approach). The entire process from data capture to visualisation on the web-portal is seamless, with no manual intervention. A similar, but less integrated, approach, has been described by Daily et al, 2004, Versteeg et al., 2006, Versteeg and Johnson, 2008.

The ALERT technology and concept has been tested in the lower Andarax basin, Almeria, where the coastal aquifer is under threat from over-exploitation, rising sea levels, anthropogenic pollutants and seawater intrusion (Pulido-Bosch et al 2006, Jorreto et al., 2007).

\section{OBJECTIVES}

The principal objectives of the project were (i) to design new instrumentation for electrical imaging that could be permanently deployed in-situ and then interrogated using wireless telemetry to provide snap-shots of the subsurface at regular intervals, thereby eliminating the need for manual repeat surveys, (ii) to relate the time-lapse geoelectric measurements to hydrogeological and hydrogeochemical properties and processes, (iii) to develop a predictive numerical modelling capability to link all 
components in the hydrologic continuum (climate, soil, surface water, groundwater recharge-discharge, and seawater intrusion-extrusion), and (iv) to develop new data fusion techniques, risk analysis and decision support tools within a web-based GIS database for the sustainable management of water resources.

This paper is concerned with the first objective only. Complementary studies on petrophysical relationships and numerical inversion, (Nguyen et al, 2005, 2007, 2008, Tsoulos et al 2006), hydrogeological modelling (Antonsson, et al., 2007, 2008) and decision support tools (Van Cauwenbergh, et al., 2008) are described elsewhere by the other project partners.

\section{THE ANDARAX COASTAL AQUIFER}

The study area selected for the project was the lower catchment of the river Andarax, Almeria, Spain, (see Fig 9).

The large surface area of the catchment (almost $2300 \mathrm{~km} 2$ ) encompasses a variety of physiographic, climatic and ecological conditions and land uses. Its climatic diversity is caused by its pronounced range in elevation $(2500 \mathrm{~m})$, stretching from the mountain ranges that form the watershed of the catchment (Sierra Nevada, Sierra de los Filabres, Sierras de Gádor and Alhamilla) down to the coast. As a result, the climatic conditions range from the high mountain climate of the Sierra Nevada in the north and north-east (receiving more than $600 \mathrm{~mm}$ mean annual precipitation) to the coastal semi-arid climate (receiving some $250 \mathrm{~mm}$ ) and the desert and sub-desert in the northeast of the catchment (200 mm annual rainfall, with marked evaporation). The climate determines both the vegetation cover and the ecosystems that occur, as well as the availability of water resources in the catchment. The river Andarax is usually dry but can be in spate two or three times each year. Despite this regime there has, in the past, been sufficient water for agriculture, forestry, and urban water supply. However, more recently, horticultural cultivation under plastic has increased significantly and current water resources, including groundwater resources, are becoming limited. There is a growing need to employ recycled or desalinated water. 
The Andarax delta is a highly dynamic zone containing numerous changes in the vertical and horizontal planes, which make it difficult to establish a hydrogeological model. The shallow Quaternary aquifer comprises three to four metres of superficial silts overlying 30 to 40 metres of coarse sediments that represent the prolongation of the alluvial deposits, (Pulido-Bosch et al, 1992, 2002). These deposits overlie finer Pliocene formations that form the impermeable base. The upper part of this marly, silty substratum contains some detritic levels, which form an artesian aquifer about $10 \mathrm{~m}$ thick, whose piezometric level is very close to that of the free aquifer. The ALERT technology was developed to help regulate pumping and assess the impacts of over-exploitation on these shallow aquifers

\section{SURVEY METHODOLOGY}

\section{ALERT system}

The ALERT prototype was deployed in the bed of the River Andarax, Almeria, in the lower part of the delta. The electrode array was buried in a trench about $1 \mathrm{~m}$ deep and nearly $1.6 \mathrm{~km}$ in length, extending upstream from a point about $300 \mathrm{~m}$ from the shoreline (Fig. 9). The riverbed is invariably dry for most of the year but flash floods often occur in the autumn and winter. The subsurface array has electrode take-outs at $10 \mathrm{~m}$ intervals. The permanent system used in the Andrarax has 288 electrodes all of which are addressable so any electrode array may be selected (e.g: Wenner, Dipole-Dipole or an optimised user-specified configuration). In this installation case however only 166 electrodes were selected. The array gave a maximum depth of investigation of $\sim 160 \mathrm{~m}$. For control purposes 3 deep boreholes were drilled through the Quaternary aquifer sediments into the relatively impermeable Pliocene marls at a depth of $\sim 100 \mathrm{~m}$. These boreholes were spaced about 500 m apart on the line of the ALERT array to provide ground-truth and to assist image calibration. Electrode arrays of $50 \mathrm{~m}$ length with take-outs at $1 \mathrm{~m}$ spacing were attached to the outer PVC casing of two of the boreholes to facilitate surface-to-hole measurements (see Fig 3). 
The ALERT instrumentation (see Fig. 4a and 4b) is located about $300 \mathrm{~m}$ from the river in secure housing, within a water treatment plant (Fig. 4c). The instrument is connected to a high capacity battery pack, batter charging source and a data communications link. It comprises a central processor that co-ordinates and controls all the major functions: data collection, storage, and transmission. Subsurface cable conduits link the instrument to the array in the riverbed.

The instrument is remotely configurable through customised software which can be run on a standard PC anywhere in the world. In this specific installation, it is linked to a BGS server via a PSTN modem interface - this being the cheapest of the available options. Other links are possible including satellite, GSM (GPRS, 3G) via a router, or by direct internet link. Once installed the system has been designed to operate around a measurement schedule linked to specific command files which contain information on both the geoelectric measurement (Resistivity, Induced Polarisation, SelfPotential), electrode selections and data acquisition parameters (e.g: duty-cycle, number of stacks, standard deviation, sampling windows). In addition the command files contain unique identifiers which allow resultant measurement data to be uploaded and automatically handled by the data management system (DMS). The system is serially based but has been configured to operate through TCP/IP protocols. Up to 100 scheduling events can be linked to locally stored command files. It is fully integrated in a single, field-hardened, water-proof sealed box, designed to withstand extreme conditions in remote localities. No PC is needed in the field. It is novel in the sense that one can install the system and literally "walk away”. A summary of the generic ALERT specifications is given in Table 1. The specific operational parameters used in the river Andarax are given in Table 2. 
Table 1. ALERT system: generic summary of functionality

\begin{tabular}{|c|c|}
\hline ALERT instrument & Situated in single waterproof housing. \\
\hline Architecture & Fully integrated no PC required in the field (install and "walk away") \\
\hline Communications & Operational options include PSTN, GSM (GPRS, 3G), satellite \\
\hline Connectors & $\begin{array}{l}\begin{array}{l}\text { Connections to electrode sensors via } 16 \\
\text { connectors }\end{array} \\
\end{array}$ \\
\hline Measurements & Resistance, Induced Polarisation, Self potential \\
\hline Setup & $\begin{array}{l}\text { Duty cycle, sampling and IP windows, delay and integration times are } \\
\text { configurable from command file }\end{array}$ \\
\hline Command file & $\begin{array}{l}\text { c1, c2, p1, p2... p11 measurement configurations, (maximum of } 3000 \\
\text { lines } \\
\text { for a single file. Other combinations possible (e.g: } 60 \text { lines if } 50 \text { file } \\
\text { configurations). }\end{array}$ \\
\hline Scheduling: & $\begin{array}{l}\text { Full day, month, year command schedule capability ( maximum } 100 \\
\text { events) }\end{array}$ \\
\hline Output capability & $500 \mathrm{v} @ 500 \mathrm{~mA}$ \\
\hline Diagnostics & $\begin{array}{l}\text { Individual measurement error and waveform ratio values returned. } \\
\text { Also full waveform can be downloaded for error analysis if required. }\end{array}$ \\
\hline $\begin{array}{l}\text { Potential } \\
\text { measurements }\end{array}$ & $\begin{array}{l}10 \text { channels using adjacent pair configurations }(\mathrm{p} 1, \mathrm{p} 2)(\mathrm{p} 2, \mathrm{p} 3) \ldots \\
\ldots(\mathrm{p} 10, \mathrm{p} 11)\end{array}$ \\
\hline Resolution & 23 bit @ 1kHz (single channel) \\
\hline Power & Battery supply (24V 170Ah) \\
\hline Charging & $\begin{array}{l}\text { Isolated 10A mains powered charger, (solar/wind turbine charging } \\
\text { option) }\end{array}$ \\
\hline Temperature range & -10 to +50 degrees $\mathrm{C}$ \\
\hline
\end{tabular}

\begin{tabular}{|l|l|}
\hline Surface electrodes & 160 deployed at 10 m inter-electrode spacing (1590 m line length) \\
\hline Borehole electrodes & $\begin{array}{l}2 \times 50 \text { electrode strings deployed separately in two 100 m deep } \\
\text { boreholes }\end{array}$ \\
\hline Data acquisition & Typically 3 hours for a single command file \\
\hline Upload time & Typically 1 minute for 3000 line command file (PSTN) \\
\hline Download time & 2245 measurement file takes $~ 24$ minutes (PSTN) \\
\hline Connection costs & $€ 1$ euro/day (for a landline) \\
\hline
\end{tabular}

Table 2. Operational parameters for the Andarax installation only 
Although the project ended in December 2007, the ALERT system is still acquiring data in real-time on a daily basis according to a pre-programmed schedule. This data is automatically captured, processed, stored in the relational database, modelled and then displayed on a web-portal for future analysis (see Fig. 5). Data has been collected using a Wenner-Schlumberger surface array and a Dipole-Dipole borehole electrode array. Reciprocal measurements were made by interchanging the current and potential electrode pairs and these results are shown in the histogram and cross-plot (Fig 6). Over $94 \%$ of all the reciprocal measurements agreed to within $2 \%$. The inversion results are also of very high quality with minimal RMS inversion errors $(<3 \%)$.

The technology has been shown to be robust and highly reliable for several years in a moderately hostile environment. Unfortunately, project funding expired before any detailed analysis of these time-lapse datasets could be carried out. This work is on-going, as and when resources permit.

\section{Data management}

The anticipated frequency of data acquisition and the unprecedented amount of raw data collected demanded a systematic approach to data processing and management. A fundamental component of the ALERT concept is the DMS, which is based upon a relational database and implements a comprehensive relational data model for time-lapse ERT data. The DMS uses a Java-based architecture for web applications with a database backend. The current deployment uses Open Source products for the relational database (MySQL) and the J2EE application server (JBoss). The use of Open Source solutions contributes to the cost-effectiveness and portability of the ALERT data management concept.

A schematic diagram of the project IT architecture is shown in Figure 9. All functionality is provided by two central servers at BGS (Fig. 4d). A Dell PowerEdge 2850 hosts the database and web application server (Fig. 4d). This machine also acts as a communications server by running customised control software, which automatically contacts the ALERT field system and controls the upload of measurement schedules and the download of measured data. A Dell PowerEdge 850 acts as a dedicated inversion server, running the numerical inversion code and accepting automated job 
submissions from the data management system (Fig. 9). 
The processing workflow for ALERT is illustrated in Figure 7. After the field system has been set up to make scheduled measurements, it is polled at predefined intervals by the communications control software, using a telemetric link as appropriate. In the case of the River Andarax site, a dedicated phone line was used to establish contact. A screenshot of the control software is shown in Figure 8. The main application window is subdivided into multiple tabs, each containing a particular aspect of functionality. The "Command Files" tab allows the registration and upload of control sequences to the system, which can then be scheduled for operation at defined times using the "Unit Schedule" tab. The "Modem Schedule" tab determines the regime in which the remote system is contacted by the communications server via the appropriate telemetric link. The "Units" tab is used to register new field systems with the software and to store and maintain important information about these systems, such as serial numbers and details on telemetry.

Once the control software has downloaded a dataset, it automatically generates a raw data file in a designated watch folder on the DMS server, using a defined ASCII file format containing metadata alongside the resistance measurements. The DMS periodically scans this folder and automatically attempts to load any raw files that appear there. Using a predetermined set of inversion parameters, the DMS will then automatically generate an input file for the appropriate inverse modelling algorithm. This file is exported to the dedicated inversion server, where the inversion software is executed when triggered by a new input file. We are using the commercial Res2dinv and Res3dinv codes developed by Loke (2008). The output files generated by the inversion are written to another designated folder periodically scanned by the DMS. A Matlab script is automatically applied to model output files, creating appropriate visual output, such as 2D resistivity cross-sections or 3D tomograms. The resulting images are then displayed using the customised web interface of the DMS. Although a high degree of automation can be achieved with this methodology, it is usually necessary after installation to manually optimise results before finally automating the data collection procedure for long-term monitoring. Once the workflow is optimised for a specific site, the process from data capture to image visualisation on the screen is seamless and automated for all further time-lapse datasets. Manual intervention is only required if automated quality checks fail or visual inspection shows large errors or dynamic changes in the image that would warrant a change in acquisition parameters (e.g: a change in 
sampling rate, or electrode configuration to better resolve a specific feature). Further developments are on-going to optimise image reconstruction (Wilkinson et al., 2006) and to program the ALERT system for adaptive sampling based on predefined scenarios (trigger thresholds) to assist the pumping schedule.

\section{Methodology for electric-hydrologic imaging}

For ALERT images to be an effective surrogate for hydrogeological monitoring it is important to have reliable petrophysical relationships for translating the electrical properties into hydrologic parameters. This work is described elsewhere (Kemna et al., 2006, Nguyen et al, 2005, 2007) and summarised in this issue (Nguyen et al, 2009). Briefly, laboratory derived relationships were used to convert the ALERT tomographic images of bulk electric conductivities (or resistivity) to water electrical conductivities. Freshwater saturated gravels are typically represented by resistivities of $1000 \mathrm{ohm} . \mathrm{m}$ or more; partially saturated sediments by $300-500$ ohm.m and saline or brackish water by $1-10$ ohm.m. The results indicate that the ALERT images can assist the recovery of hydrological parameters (e.g. salinity mass fraction) with a high degree of certainty and hence map the seawaterfreshwater interface.

Figure 10 shows a 2D ALERT image superimposed on an aerial photograph of the delta region. The image shows the influence of deep conductive saline water (dark blue), unsaturated surficial sediments (red) and a freshwater-saltwater mixing zone (green). The white dots denote buried electrode locations. The results show an increase in the depth of the saline interface inland, as expected. However, contrary to expectations, this image remained largely unchanged for the duration of the 3 year project. The Andarax coastal aquifer system is complex and this behaviour is not easily explained. Our studies showed that large annual variations in inland hydraulic head levels (up to $7 \mathrm{~m}$ ) did not generate corresponding hydraulic head variations in the delta area (Antonsson et al, 2007). These tend to be only about 0.3 - $0.4 \mathrm{~m}$. Thus, it appears that seasonal, annual or even hydraulic head changes over a few years have little effect on the hydraulic head in the delta area, indicating that the inland hydraulic head response and delta hydraulic head response are only weakly coupled. This 
limited connection explains why we observe only very small, if any, changes in the saltwater intrusion front. The primary factor controlling the saltwater intrusion in the coastal zone was found to be groundwater pumping for agriculture and horticulture irrigation, not natural forcing.

\section{Time-lapse images}

During the project anthropogenic activity had little short-term impact on the saltwater interface imaged by the ALERT installation. However, the flash floods that occur in the River Andarax during periods of high rainfall (mainly in the autumn) did induce detectable changes. These transient floods usually only last a day or two and hence the impact on recharge is rarely, if ever, captured by traditional sampling.

Such a flood occurred on the $22^{\text {nd }}$ September 2007 (Fig 12). Fig 11 shows a sequence of timelapse resistivity images captured by ALERT on the $19^{\text {th }}, 21^{\text {st }}$ and $22^{\text {nd }}$ September, 2007. The data from the 19th September 2007 were inverted using the Res2DInv software, with a finite-difference method, a complete Gauss-Newton solver, an $L_{2}$ (smoothness) model constraint, an L2 (least-squares) data constraint, using the logarithms of the apparent resistivity data for stability (Loke and Barker, 1995, Loke et al., 1996). Subsequent data sets were inverted using time-lapse constraints to reduce image artefacts caused by data noise. Each subsequent set was inverted simultaneously with that from the $19^{\text {th }}$, and used the preceding inversion as a reference model (i.e. the inversion of the $21^{\text {st }}$ September data used the $19^{\text {th }}$ September model as a reference; the $22^{\text {nd }}$ September data used the $21^{\text {st }}$ September model as a reference). An L2 constraint was imposed on the differences between subsequent models. The RMS misfit errors for the $19^{\text {th }}, 21^{\text {st }}$ and $22^{\text {nd }}$ September inverted models were $1.2 \%, 1.2 \%$, and $2.7 \%$ respectively. 
The differential or sequential image (Fig. 11c) shows no change from the $19^{\text {th }}$ to $21^{\text {st }}$ September but during the flash flood on the $22^{\text {nd }}$ September there is clear evidence of infiltration. Although most of the surface water discharges as run-off into the Mediterranean Sea, the drop in formation resistivity (shown in blue in Fig 11(e)) can be attributed to freshwater saturation of the near-surface sediments. The increase in resistivity immediately below this drop (in red in Fig 11(e)) is probably an artefact of using a 2D inversion model for a heterogeneous 3D structure. It is likely that the larger misfit for the $22^{\text {nd }}$ September is due to larger resistivity contrasts caused by floodwater at or near the surface electrodes. Such subtle effects are often difficult to detect with manual repeat surveys due to the inherent errors associated with re-locating the electrode positions. This illustrates the inherent benefits of permanent or semi-permanent arrays.

\section{CONCLUSIONS}

Preliminary assessment of the time-lapse ALERT images confirms that this technology can be used to map and monitor saltwater intrusion with greater confidence and efficiency than would be possible by the traditional sampling of wells. The results are supported by both 3D density-dependent flow models for the Andarax region and by localised measurements in deep boreholes. By tracking the freshwater-seawater interface from the ALERT images in near real-time, water resource managers and local regulatory authorities could assess the impact of pumping and irrigation on the aquifer depletion rate. This effectively removes, or at least minimizes, the need for the manual sampling of water samples and time-consuming laboratory analysis. This technology should not only permit a more sustainable approach to water management and conservation, but will provide temporal and spatial sampling at a rate which has not previously been possible. ALERT should greatly assist our understanding of hydrologic processes in coastal aquifers, and provide more reliable evidence for high-level water management strategies, decision making, and/or regional development planning.

\section{ACKNOWLEDGEMENTS}

The work described in this paper was undertaken in support of the ALERT Project for the European Union Sixth Framework Programme, Contract No. GOCE-CT-2004-505329. The ALERT 
consortium partners were: British Geological Survey, Forschungszentrum Juelich GmbH, University of Copenhagen, Universidad de Almeria, Universite Catholique de Louvain, Aristotle University of Thessaloniki, Industrial Research Institute for Automation and Measurements, ESCO Sp. Zo.o.,

Geotomographie, Cadi Ayyad University of Marrakech. This paper is published with the permission of the Executive Director of the British Geological Survey (NERC). 


\section{REFERENCES}

Antonsson, A, Engesgaard, P., Jorreto, S., Pulido Bosch, A., 2007. A modelling study of saltwater intrusion in the Anadarax delta using multiple data sources. In Proceedings TIAC'07 International Conference on Technology of Seawater Intrusion in Coastal Aquifers, Almeria, Spain, 16-19 Oct. 2007.

Antonsson, A, et al...this issue 2009.

Daily, W., Ramirez, A., Newmark, R., Masica, K., 2004. Low-cost reservoir tomographs of electrical resistivity. The Leading Edge, May 2004, 472- 480.

Grellier, S., Guerin, R., Robain, H., Bobachev, A., Vermeersch, F. and Tabbagh, A., 2008. Monitoring of Leachate Recirculation in a Bioreactor Landfill by 2-D Electrical Resistivity Imaging. Journal of Environmental and Engineering Geophysics, 13(4): 351-360.

Johansson, S. and Dahlin, T., 1996. Seepage monitoring in an earth embankment dam by repeated resistivity measurements. European Journal of Engineering and Environmental Geophysics, 1(3): $229-247$.

Jorreto, S., Pulido-Bosch, A., Sánchez-Martos, F., Engesgaard, P., Francés, I., Gisbert, J., 2007. Dynamic of the freshwater-seawater contact in coastal aquifers with high abstraction of seawater. In: Coastal aquifers: challenges and solutions. Vol. I: 989-996. A. Pulido Bosch, J. A. López Geta and G. Ramos (Eds), PIGME Publications. Hydrogeology and Groundwater Series number 23.

Kemna, A., Nguyen, F., Antonsson, A., Engesgaard P., and Tsourlos, P., 2006. Characterization of saltwater intrusion using electrical imaging: a numerical simulation study. A. In Proceedings: 1st International Joint Salt Water Intrusion Conference (SWIM-SWICA), 2006, Calgiari, Italy, September 24-29.

Kuras O., Meldrum, P I, Ogilvy R D., Gisbert, J., Jorreto S, and Sánchez Martos F, 2005. Imaging seawater intrusion in coastal aquifers with electrical resistivity tomography: initial results from the lower Andarax delta, SE Spain. In Proceedings, 11th Annual Meeting EAGE-NearSurface Geophysics Conference, Palermo, Sicily, Italy, September, 2005. 
Loke, M. H., and Barker, R. D., 1995, Least-squares deconvolution of apparent resistivity pseudosections. Geophysics, 60, 1682-1690.

Loke, M.H. and Barker, R. D., 1996. Practical techniques for 3D resistivity surveys and data inversion. Geophysical Prospecting, 44, 499-523.

Loke, M. H., 2008. Geotomo Software Sdn. Bhd. www.geoelectrical.com/.

Nguyen F., and A. Kemna, A., Strategies for Time-Lapse Electrical Resitivity Inversion. In Proceedings, 11th Annual Meeting EAGE-Environmental and Engineering Geophysics, Palermo, Sicily, Italy, September 2005.

Nguyen, F., Kemna, A. Antonsson, A., Engesgaard, P., Kuras, O., Ogilvy, R. D., Gisbert, J., Jorreto S., and Frances, I., 2007. Contribution of 2D electrical imaging for seawater intrusion calibration. In Proceedings TIAC'07 International Conference on Technology of Seawater Intrusion in Coastal Aquifers, Almeria, Spain, 16-19 October 2007.

Nguyen F., et al, 2009............this issue.

Ogilvy, R D, Kuras, O, Meldrum, P I, Wilkinson, P B, Chambers J E, Gisbert J., Jorreto S, Pulido Bosch A, Kemna A, Nguyen F., and Tsourlos P. 2007. Automated Monitoring of Coastal Aquifers with Electrical Resistivity Tomography. In Proceedings TIAC'07 International Conference on Technology of Seawater Intrusion in Coastal Aquifers, Almeria, Spain, 16-19 Oct. 2007.

Ogilvy, R D, Meldrum, P I, Kuras, O., Wilkinson, P B, and Chambers J E., 2008. Advances in Geoelectric Imaging Technologies for the Measurement and Monitoring of Complex Earth Systems and Processes. In Proceedings 33rd International Geological Congress, Oslo, Norway, 10 -14 August 2008.

Pulido-Bosch A., Calaforra, J M, Vallejo A, Sanchez-Martos, Gisbert, J, Ogilvy, R D, Vanclooster M, Frances I, Jorreto S, Diaz-Curiel, Kuras O, Meldrum P I., 2006. Water scarcity, Coastal Aquifers and Desalination Plants. In Proceedings, IAH International Congress, Marrakech, Morocco, May 2006. 
Pulido-Bosch, A., Sánchez-Martos, F. Martínez-Vidal, J.L. and Navarrete, F. (1992). Groundwater problems in a semiarid area (Low Andarx River, Almería, Spain). Environ. Geol. Water Sci. 20 (3): 195-204.

Pulido-Bosch, A., Pulido Leboeuf, P., Sánchez Martos, F., Gisbert, J. and Vallejos, A. (2002). Coastal aquifers and desalinisation plants. A case study: Almería, Spain. In: Groundwater Hydrology. Sherif, Singh \& Al-Rashed Eds. Balkema. Vol. 2: 415-434.

Tsourlos, P, Ogilvy R D, Meldrum P. I., and Williams G. M., 2003. Time-lapse Monitoring in Single Boreholes Using Electrical Resistivity Tomography. Journal of Environmental and Engineering Geophysics, Vol.8, No. 1, 1-14.

Tsourlos, P., Athanasiou, E., Kuras, O., Wilkinson P. B, and Ogilvy, R D., 2006. Optimizing ERT measurements for hydrogeological monitoring: the case of Almeria (Spain). In Proceedings, 12th Annual Meeting EAGE-Near Surface Geophysics, Helsinki, Finland, September, 2006.

Van Cauwenbergh, N., Pinte, D., Tilmant, A., Frances, I. , Pulido-Bosch, A, and Vanclooster, M. 2007. Multi-objective, Multi-participant Decision Support in the Andarax Catchment, Almeria. Environmental Geology, Vol. 54, No. 3, 479-489.

Versteeg, R., Ankeny, M., Harbour, J., Heath, G., Kostelnik, K., Mattson, E., Moor, K., Richardson, A. and Wangerud, K., 2004. A structured approach to the use of near-surface geophysics in long-term monitoring. The Leading Edge, 23(7): 700-703.

Versteeg, R.J., Richardson, A.N. and Rowe, T., 2006. Web-accessible scientific workflow system for performance monitoring. Environmental Science \& Technology 40: 2692 - 2698.

Versteeg R., and Johnson T., Using time-lapse electrical geophysics to monitor subsurface processes. The Leading Edge, November 2008. 1488- 1497

Wilkinson, P B., Meldrum, P I., Chambers, J E., Kuras, O., and Ogilvy, R D., 2006. Improved strategies for the automatic selection of optimized sets of electrical resistivity tomography measurement configurations. Geophysical Journal International, Vol 167, 1119-1126. 


\section{ILLUSTRATIONS}

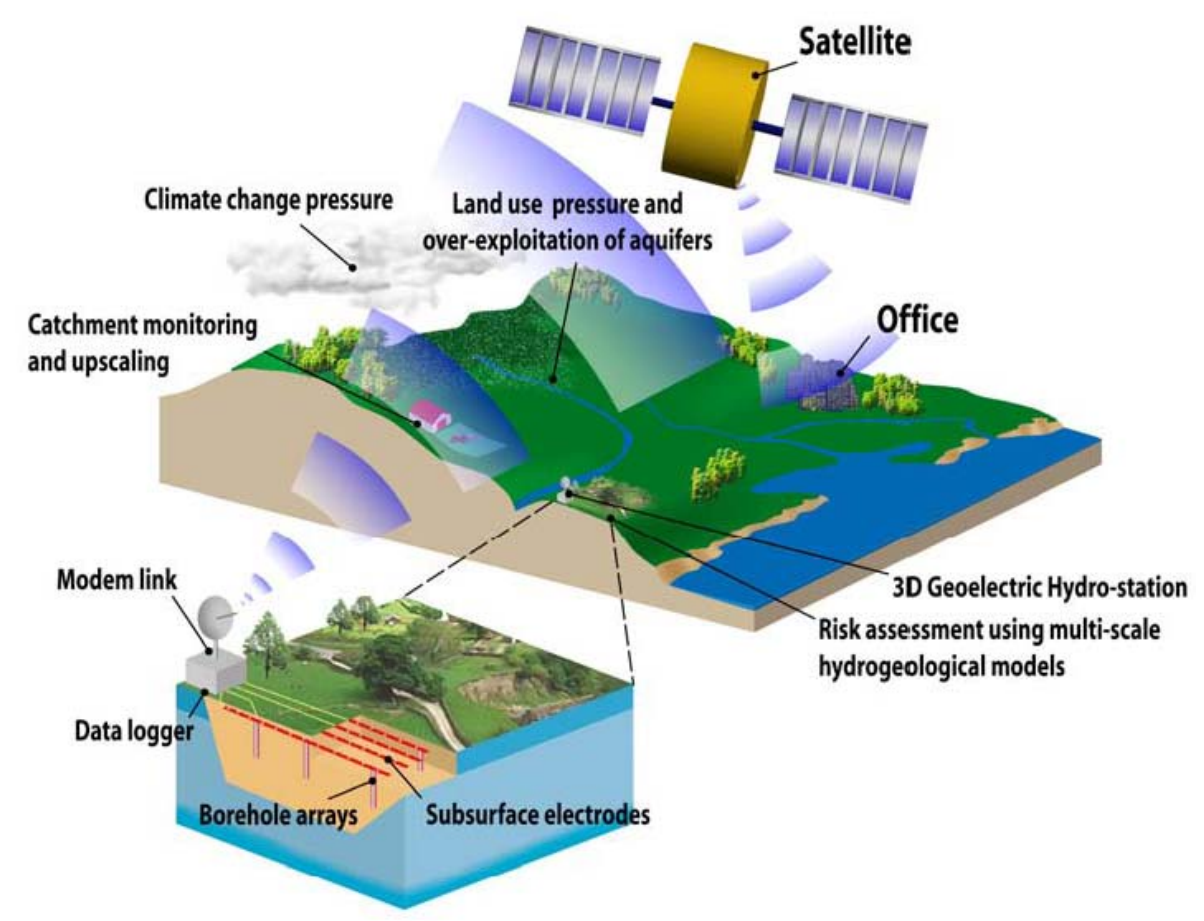

FIGURE 1. Schematic ALERT concept showing buried ERT arrays and remote data transmission.

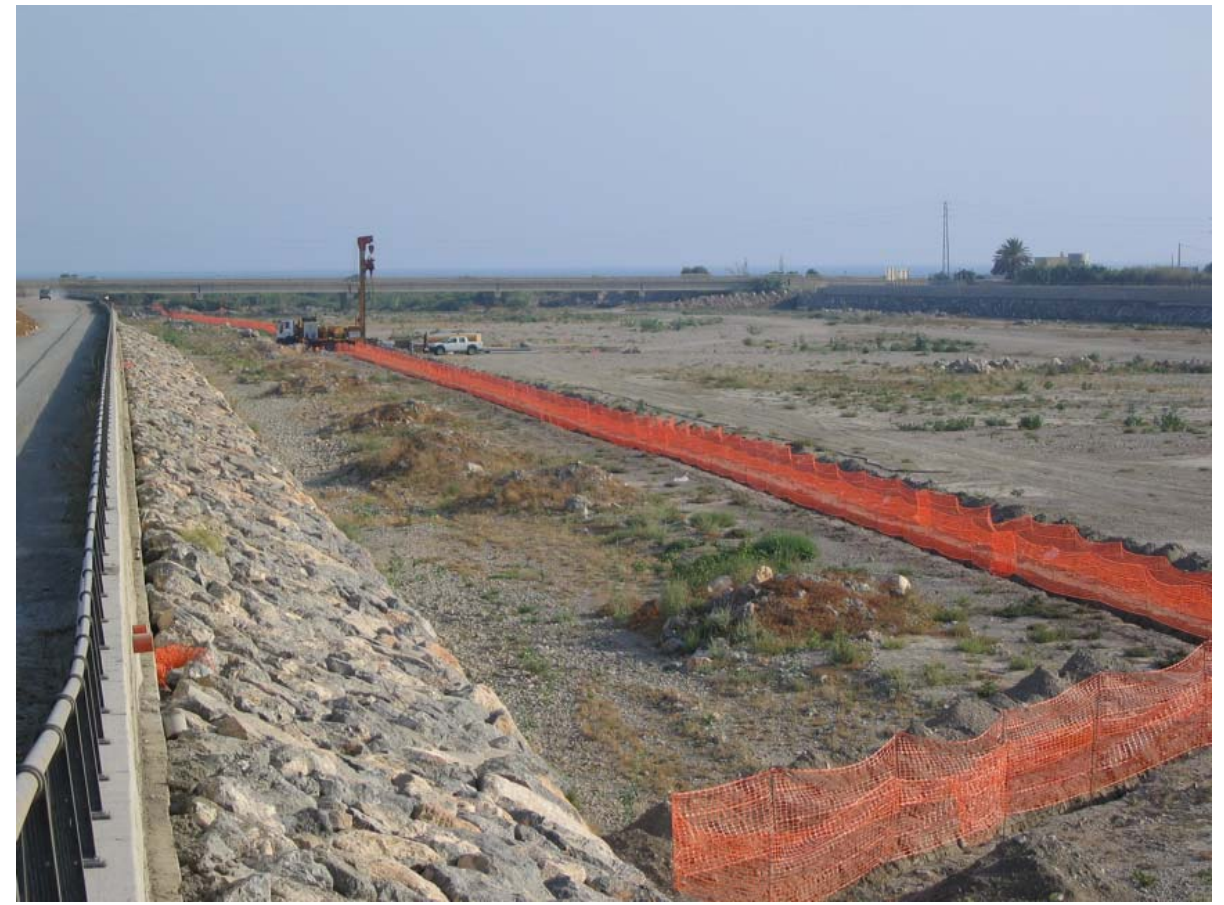

FIGURE 2. Excavation of the ALERT trench and drilling 


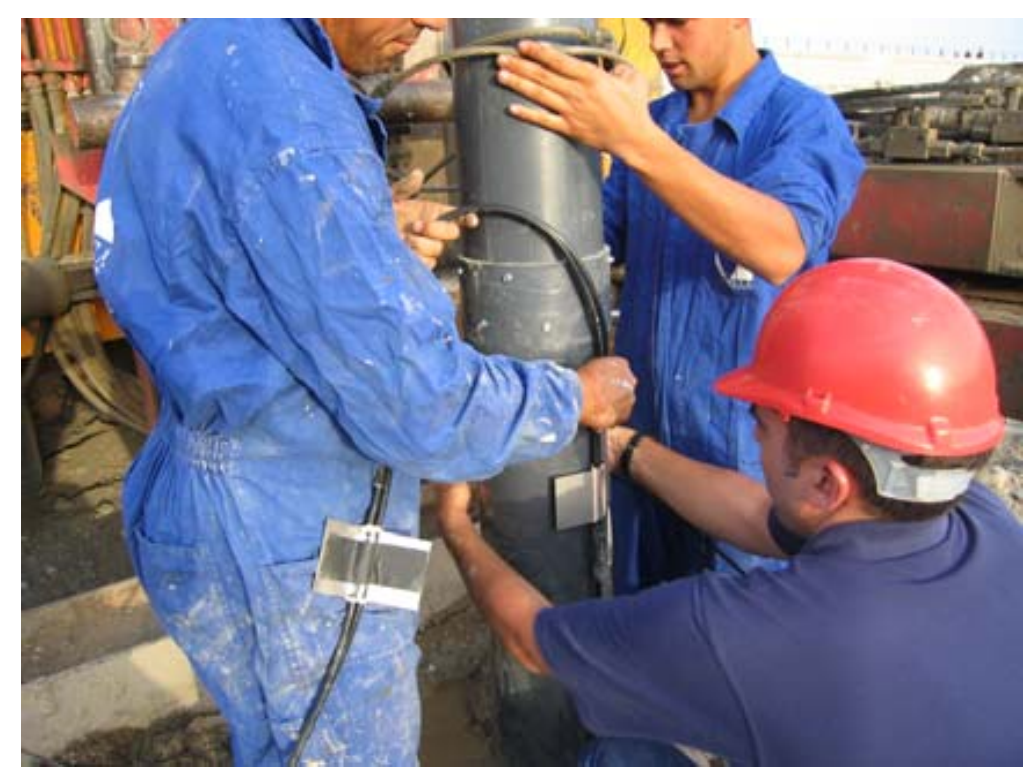

FIGURE 3.

Attaching downhole electrodes to borehole casing during drilling 
FIGURE 4 Fully integrated ALERT prototype showing (a) external and (b) internal views, (c) secure housing for ALERT instrument, (d) two Dell PowerEdge project servers in BGS: one for the DMS and one for numerical modelling

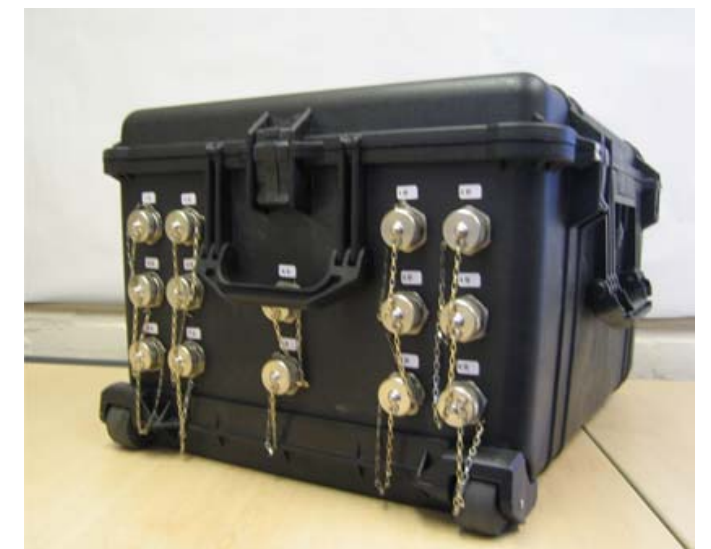

(a)

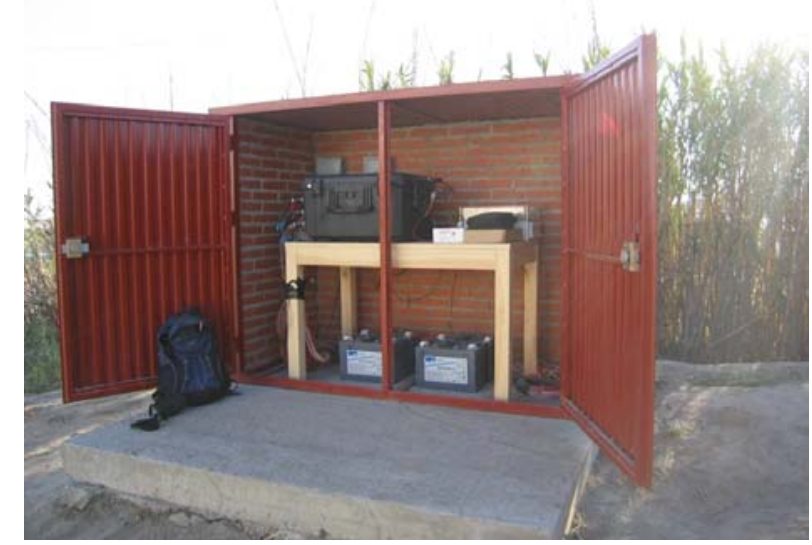

(c)

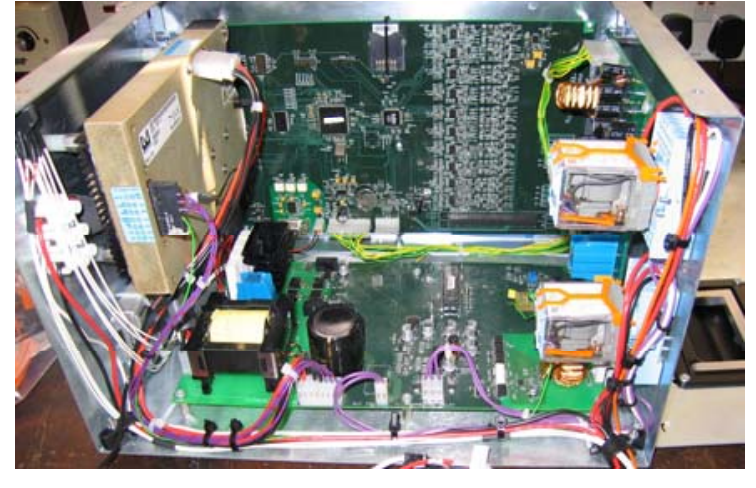

(b)

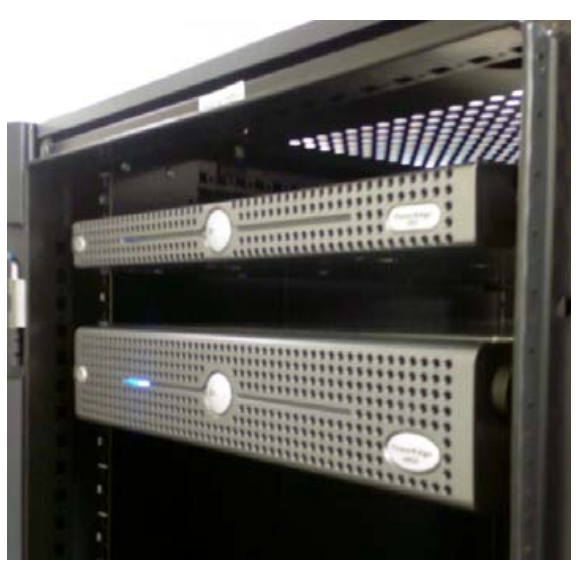

(d) 


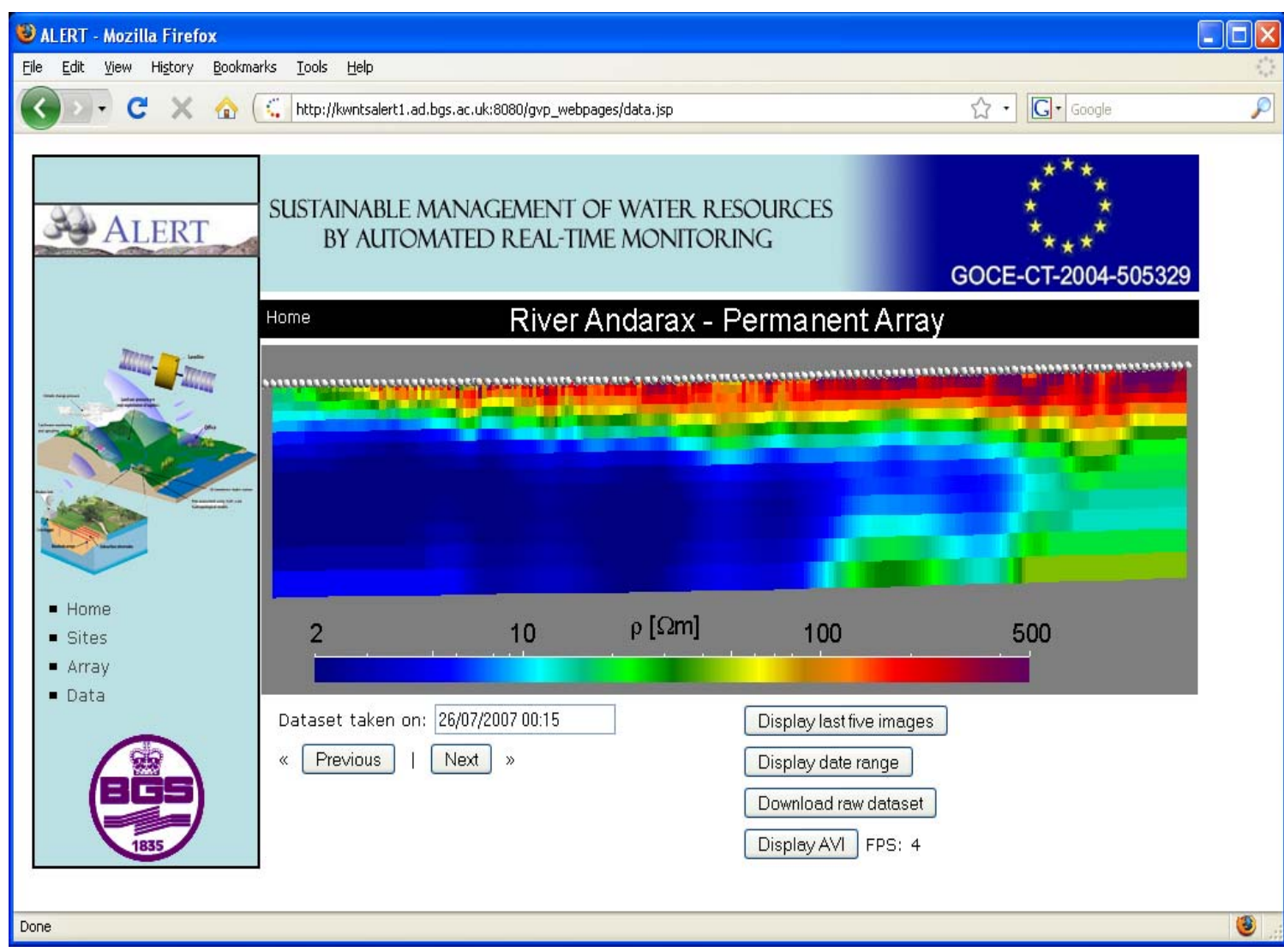

FIGURE 5 Screen-shot of web-portal 

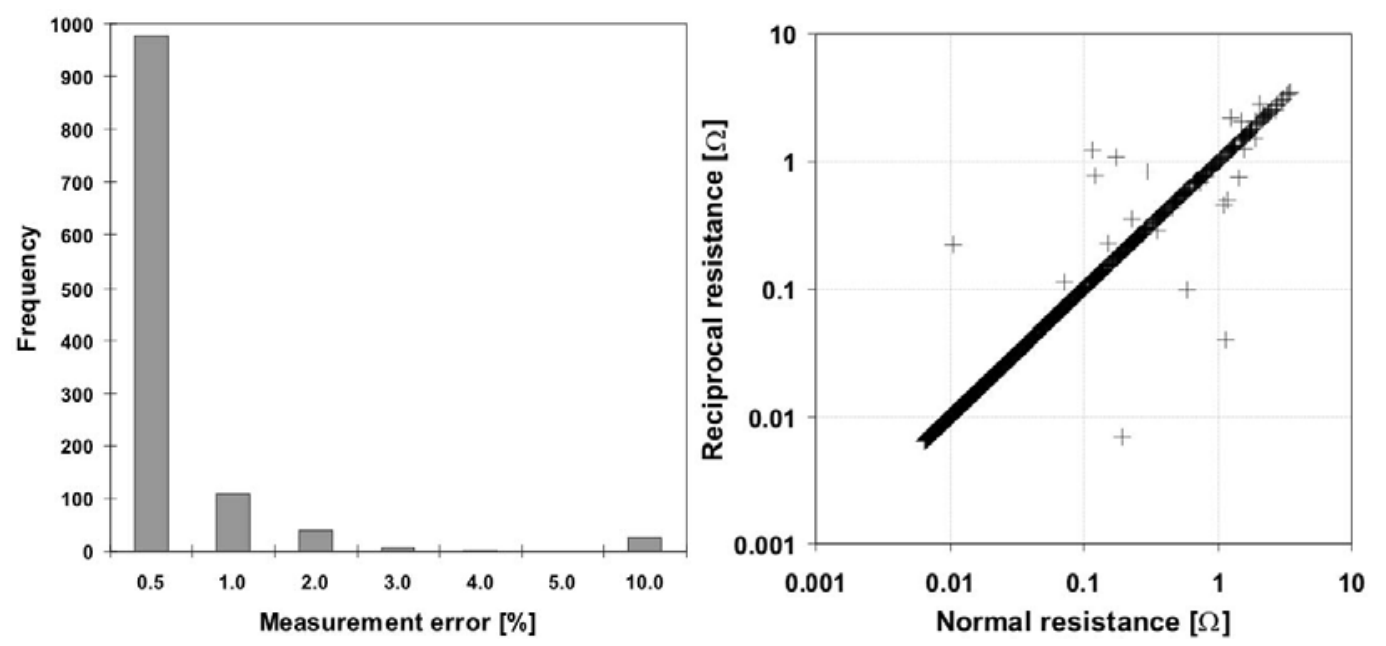

(a)

(b)

FIGURE 6 Data quality: (a) histogram and (b) cross-plot of reciprocal electrode pair measurements for the Wenner-Schlumberger array, (1165 data pairs).

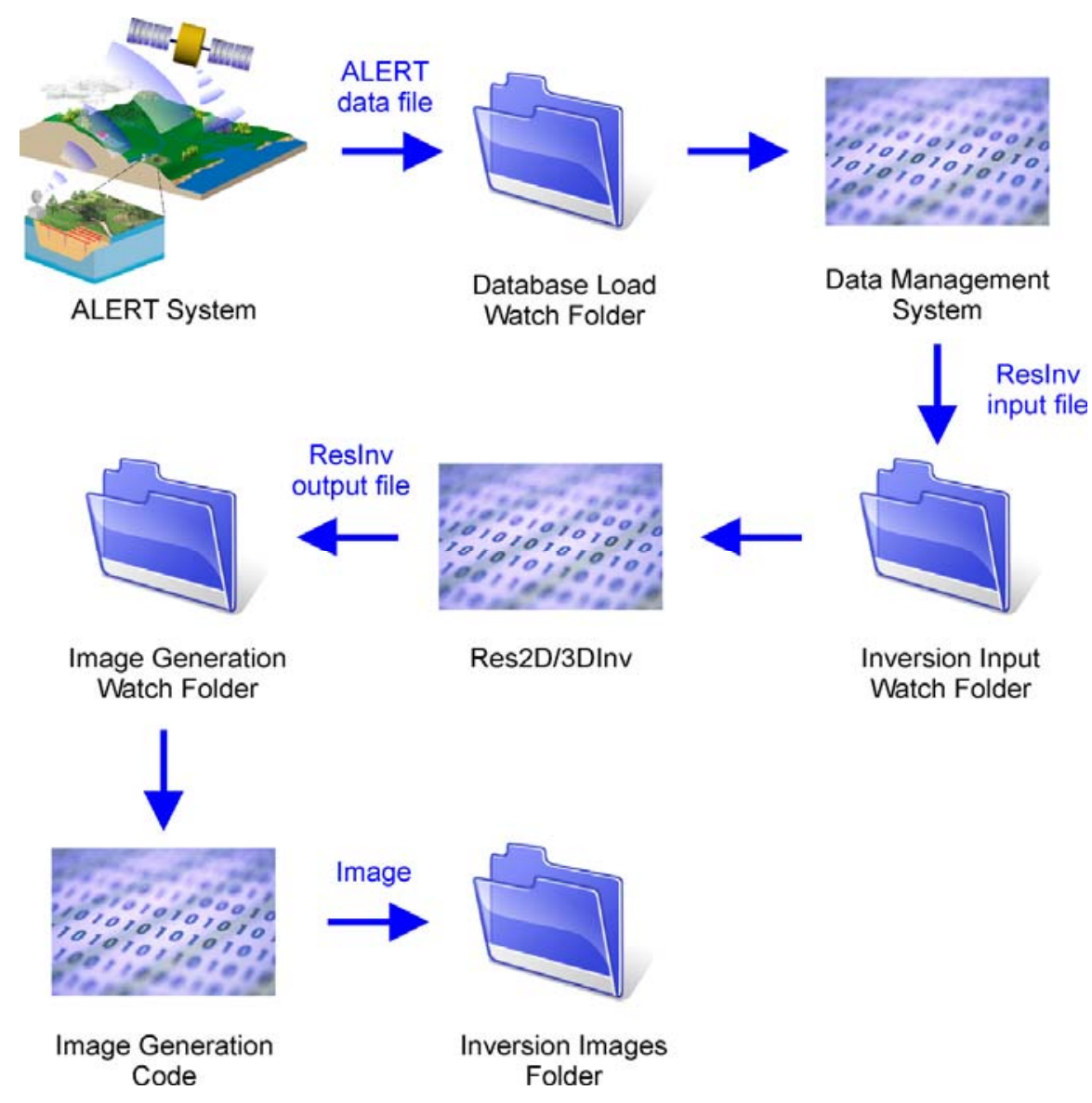

FIGURE 7 Data processing pipeline 


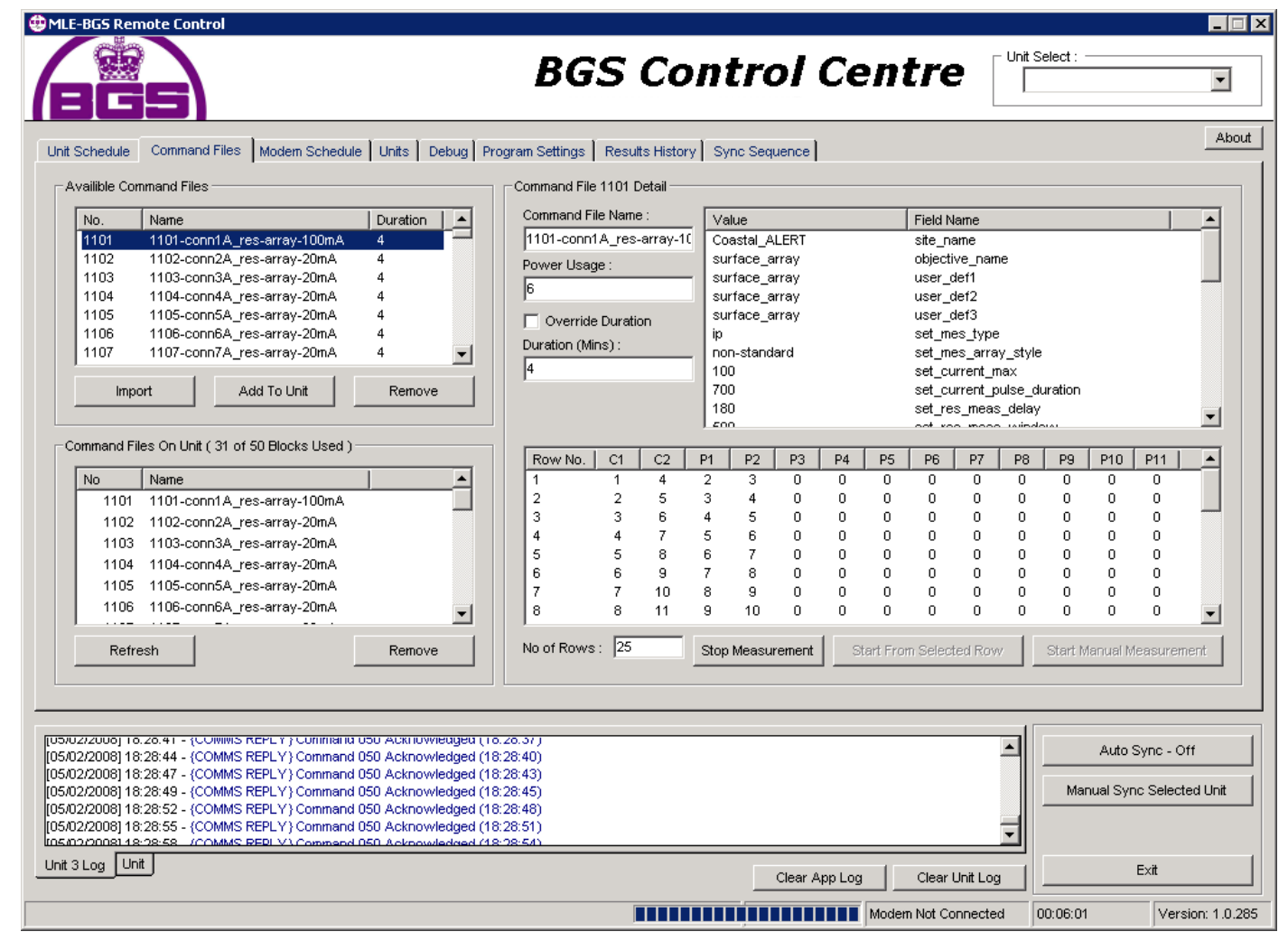

FIGURE 8 Screenshot of the "Command Files" tab of the PC Scheduler software used to remotely control the ALERT instrumentation.

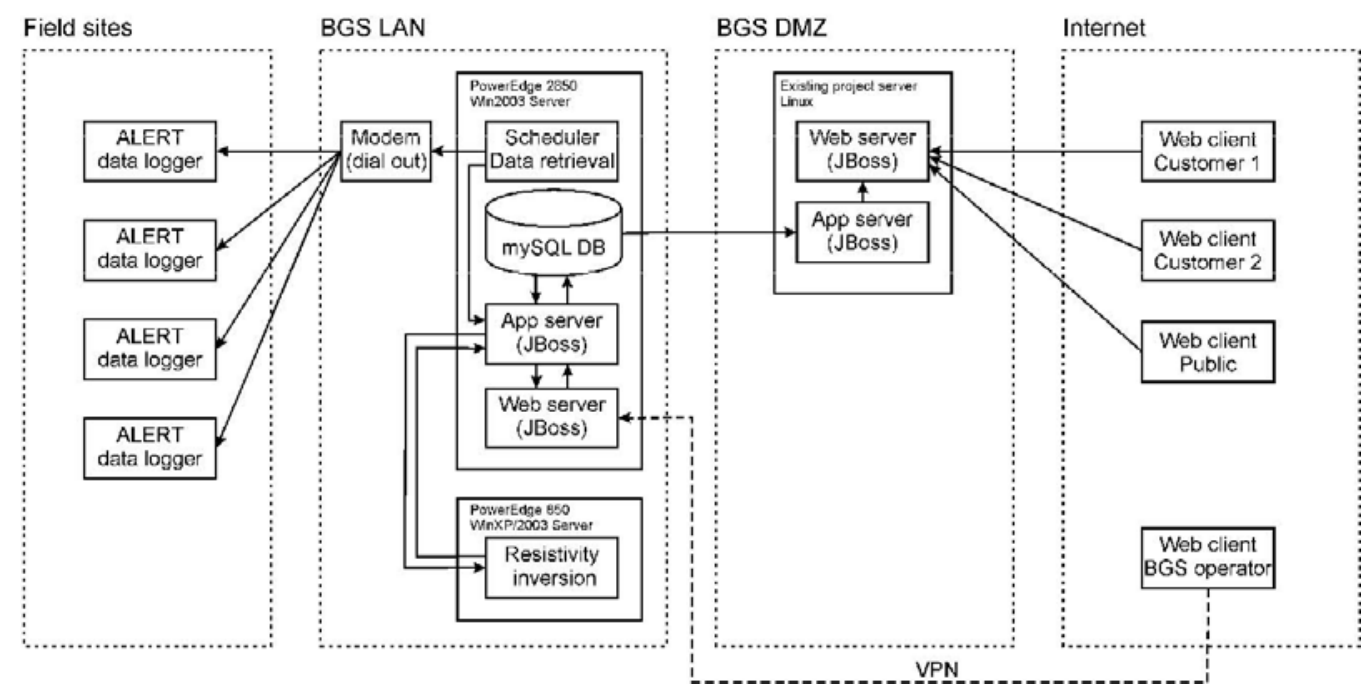

FIGURE 9 Schematic diagram of the ALERT IT architecture. 
FIGURE 10

Aerial photograph with 2D ALERT image overlay. Visualisation of the subsurface aquifer

showing conductive saline water (blue), resistive freshwater (red) and a mixing zone (green).

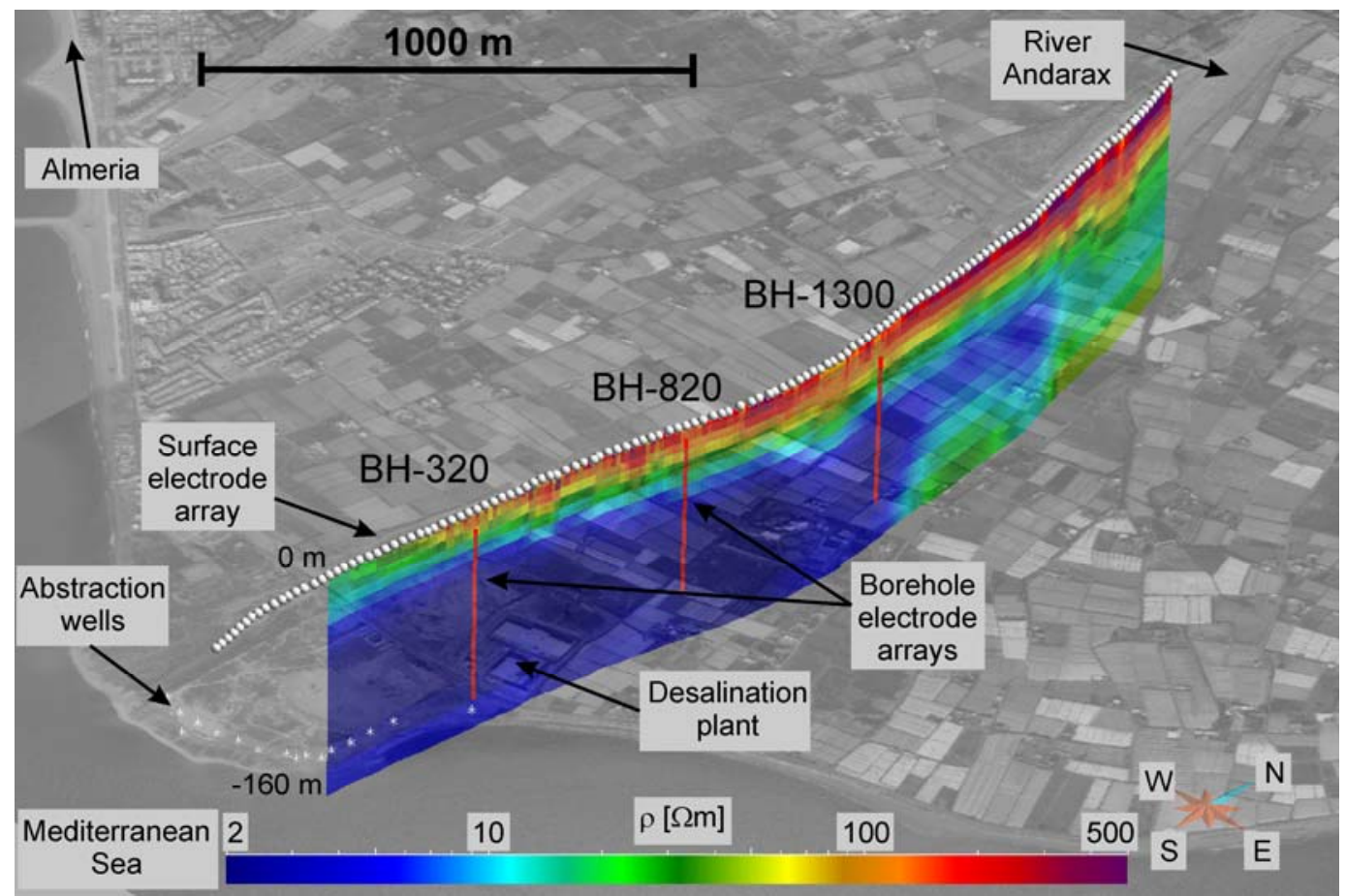


(a)

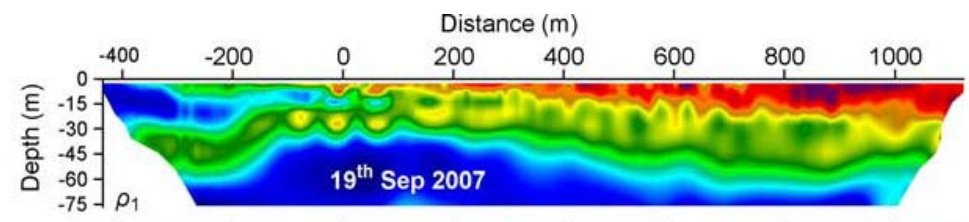

(b)

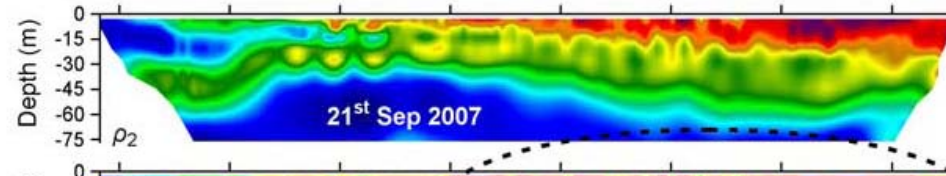

(c)

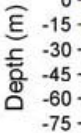
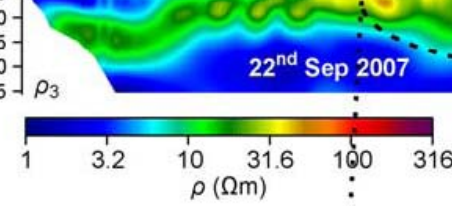

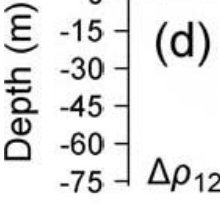

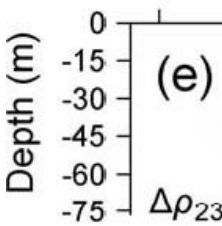

$\rho_{23}$

FIGURE 11 2D ALERT images (a) and (b) before the flash flood, (c) the day of the flood and (d) the differential image before the flood showing no change and (e) the differential image on the day of the flood showing significant near-surface infiltration. 


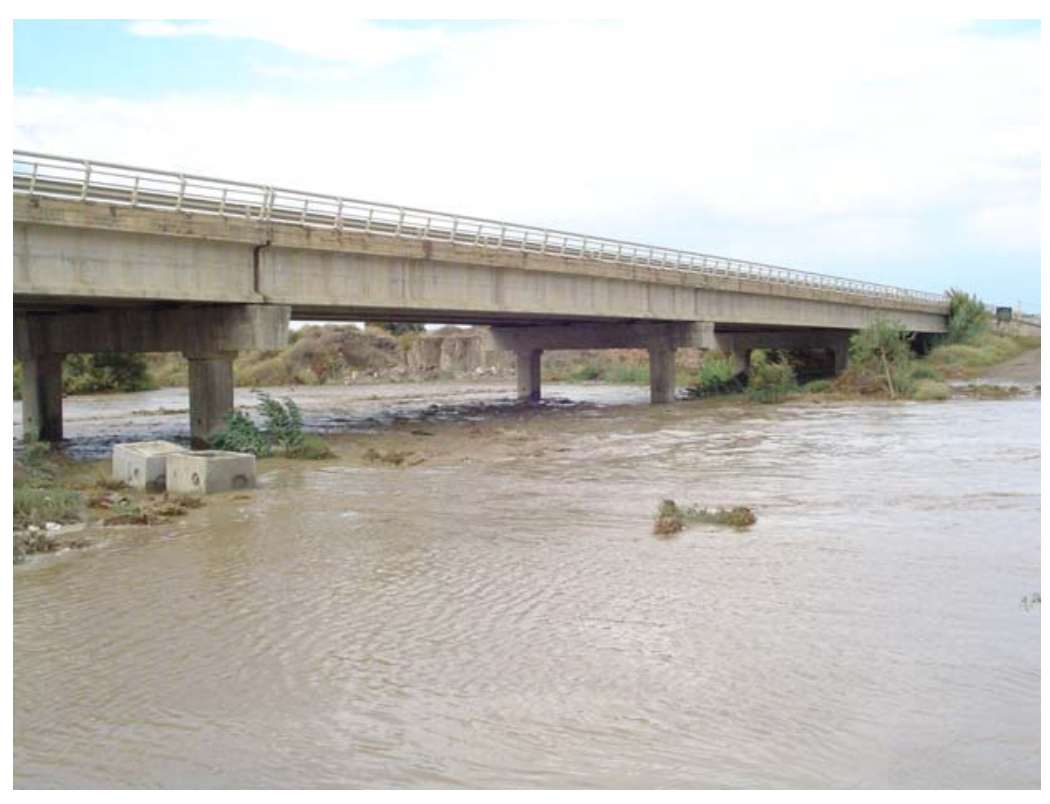

FIGURE 12 Flash flood, River Andarax 


\section{FIGURE CAPTIONS}

FIGURE 1 Schematic ALERT concept showing buried ERT arrays and remote data transmission.

FIGURE 2 Excavation of the ALERT trench and drilling

FIGURE 3 Attaching downhole electrodes to borehole casing during drilling.

FIGURE 4 ALERT instrument: (a) external and (b) internal views, (c) secure housing for ALERT instrument in Water Treatment Plant compound and (d) Dell PowerEdge project servers in BGS: one for the DMS and one for numerical modelling

FIGURE 5 Screen-shot of web-portal

FIGURE 6 Data quality: (a) histogram and (b) cross-plot of reciprocal electrode pair measurements for the Wenner-Schlumberger array, (1165 data pairs).

FIGURE 7 Data processing pipeline

FIGURE 8 Screenshot of the "Command Files" tab of the PC Scheduler software used to remotely control the ALERT instrumentation.

FIGURE 9 Schematic diagram of the ALERT IT architecture.

FIGURE 10 Aerial photograph with 2D ALERT image overlay. Visualisation of the subsurface aquifer showing conductive saline water (blue), resistive freshwater (red) and a mixing zone (green)

FIGURE 11 2D ALERT images (a) and (b) before the flash flood, (c) the day of the flood and (d) the differential image before the flood showing no change and (e) the differential image on the day of the flood showing significant near-surface infiltration.

FIGURE 12 Flash flood, river Andarax

TABLES

Table 1. $\quad$ ALERT system: generic summary of functionality

Table 2. Operational parameters for the Andarax installation only 